\title{
AUTOMATED LANDSLIDE MONITORING AND WARNING USING RADIO FREQUENCY IDENTIFICATION TECHNOLOGY
}

\author{
J. MAJROUHI SARDROUD ${ }^{1}$, S. HOSSEYNI ${ }^{2}$, E.N. BROMHEAD ${ }^{3} \&$ M. RIAZI ${ }^{4}$ \\ ${ }^{1}$ Faculty of Engineering, Islamic Azad University, Central Tehran Branch, Tehran, Iran. \\ ${ }^{2}$ Faculty of Engineering, Islamic Azad University, Azadshahr Branch, Iran. \\ ${ }^{3}$ School of Civil Engineering, Faculty of SEC, Kingston University, UK. \\ ${ }^{4}$ Shaloodeh Khak Consulting Engineers, Gorgan, Iran.
}

\begin{abstract}
Every landslide catastrophe causes a significant loss to human lives and their assets. These losses have increased as human development has expanded into unstable hill slopes. Thus, monitoring of landslides has received great attention over the past years. Water content and pore-water pressure in the slope areas strongly affect the instability of slops. Therefore, groundwater level is an essential element of the landslide investigation and monitoring. On the other hand, modeling of groundwater is difficult due to the complex internal geology in most landslides prone areas. This research investigates an innovative technique, based on Radio Frequency Identification (RFID) technology combined with ultrasonic sensors for accurate and timely identification and monitoring of groundwater level in slopes and landslide susceptible areas. The integrated monitoring and early warning system is continuous and traceable, which is able to monitor groundwater in landslide susceptible areas on a real-time basis and to reliably deliver data to a data management center. The transmission of data to the central database can be carried out with the help of Global System for Mobile Communications (GSM), and the collected data can be used for slope stability analysis in order to provide real time susceptibility maps. The autonomous (24/7) operation function and effective data transmission of the proposed system can be considered an essential tool for early warning and verification of landslide activity by allowing the user to be warned automatically at the onset of landslide occurrence.
\end{abstract}

Keywords: Automated landslide monitoring, GPRS, groundwater level, RFID, ultrasonic.

\section{INTRODUCTION}

Landslide is one of the most common devastating disasters, which in many parts of the world affect urban settlements and infrastructures. This complex geological and geomorphological process occurs when the resistance of the soil or rock deteriorates. Human development in unstable hill slopes increased the incidence of landslide disasters, recently. Although stabilization projects are an alternative treatment for unstable slopes, they are sometimes impracticable and not cost-effective. Those situations necessitate an adequate safety level for landslide prone areas, in which monitoring and early warning system, as a powerful tool, plays an essential role in identifying movements in advance to decrease the number of fatalities and casualties. Monitoring also is a way of understanding landslide processes to predicate future morphological changes to protect human lives. There are different approaches to detect the ground movements such as: the use of survey markers; extensometers; inclinometers; analog and digital photogrammetry, both terrestrial and aerial; and Interferometric Synthetic Aperture Radar (InSAR) and Ground-based Synthetic Aperture Radar (GB-SAR) and recently Web Geographical Information System platform (WebGIS) [1-5].

Combinations of GPS methods and SAR interferometry have been developed by Peyret et al. [6] to monitor a large slow landslip in the Alborz Mountain Range in Iran. This combination of geodesy and field observation leads to a precise description of the past and present kinematic behavior of the landslide. Borgogno Mondino et al. [7] have proposed an innovative 
image ortho-projection method based on a multi-layer perceptron neural network to correct multi-spectral infrared and visible imaging spectrometer images of a test area in Italy. A new complex translational landslide evolving into mudflows was monitored using an experimental system based on terrestrial Light Detection and Ranging (LIDAR) and GPS technologies by Baldo et al. [8]. This system allowed the monitoring of the morphologic and volumetric evolution of the landslide based on geological and geomorphological field surveys. Recently an application of Wireless Sensing Networks has been investigated for landslide monitoring and early warning [9]. Although this method has the capability to provide continuous information, with damage to a sensor all the network would lose its effectiveness. Furthermore, in recent research by Hosseyni et al. [10], Radio Frequency Identification (RFID) application for surface and subsurface ground detection has been investigated.

Among the main causal factors of landslides, the temporal variation of the groundwater level plays an important role on slope instability, so that it can be said that the groundwater level is often the primary controlling factor in landslide occurrence. Recently, investigations have been carried out for modeling and estimating groundwater level in various conditions [11]. The distributed three-dimensional (3D) groundwater model MODFLOW has been applied to evaluate the groundwater processes of the hydrogeological system within GIS [12]. Soil moisture was assessed by an airborne scatterometer by Blumberg et al. [13]. They developed a multi-channel system as a remote sensor for mapping soil water content. In 2002, dynamic groundwater movement was monitored using Ground Penetration Radar (GPR) by Sati et al. [14]. Water behavior inside the soil was simulated by a two-dimensional (2D) simulation model for predicting rainfall-triggered landslides [15]. Groundwater numerical modeling has been used to understand the patterns of groundwater flow in slopes and their impact on slope stability by several researchers [16]. An investigation of slopes endangered by rainfall-induced landslides using high-resolution 2D and 3D electrical resistivity tomography (ERT) was carried out to derive detailed subsurface images by Friedel et al. [17]. Multi-temporal images for groundwater level monitoring in arid areas was used in 2008 by Pan et al. [18]. A time domain reflectometry-based probe was used for monitoring water content in a high-clay landslide by Stangl et al. [19]. The results from soil moisture probes and water levels revealed the surface infiltration process in an unsaturated soil so that the mechanism of failure of rainfall-induced landslides could be understood by Tu et al. [20] in the same year. Environmental sensors and sensor networks to develop water and salinity budgets for seasonal wetland real-time water quality management were investigated in 2010 by Quinn [21].

To develop a real-time monitoring system for groundwater level change and to provide the basic information, this research investigates RFID-based system which is combined with sensor technologies and other traditional groundwater monitoring techniques and rainfall gauges. It gives a regional seasonal picture of groundwater level in the endangered areas. Data can be captured and saved continuously, far from the site in any weather condition even during landsliding. For best effect, automated record data systems should be coupled with dynamic software to acquire and save real-time continuous data and to visualize groundwater table areas.

\section{PROBLEM STATEMENTS}

Landslide monitoring systems usually concentrate on ground movement, as this gives direct indication of developing instability. Groundwater monitoring on the other hand, needs to be interpreted through an appropriate stability model to be useful. It is important, therefore that if groundwater monitoring is undertaken, that the measurement of water level is made in real 
time and is transmitted to a safe remote location for processing. The problems therefore lie within the areas of both data collection and transmission.

The following section describes the three basic technologies used in a data collection and transmission system. They are ultrasonic sensors to measure the depth to the water table, driven by an RFID tag that can be activated remotely, and the GSM connection for data transmission.

\section{WIRELESS TECHNOLOGIES}

Recent technological advancement in wireless sensor technologies and data acquisition systems provides potential for advanced consistent data collection and communication and are both technically and economically feasible and viable [21,22].

\subsection{RFID systems}

RFID system is a form of Auto-ID technology by interrogating a unique characteristic of the physical object using radio waves. It can be considered as the next generation of barcode, which uses radio waves rather than light waves to read a tag. Two decades ago, RFID was introduced as the ultimate replacement for Barcode. In other words, RFID is an automatic identification method that is based on the detection of electromagnetic signals, and radio frequencies are used to capture and transmit data from and to a tag [23, 24].

The RFID system works with a reader emitting electromagnetic waves (a radio signal), and a magnetic field is created when the signal from the reader couples with the tag's antenna [25]. A typical RFID system is shown in Fig. 1.

The signal activates the tag and the tag draws its power from this magnetic field, which enables the tag to send back an identifying response to the reader through the same RF wave. The reader then converts the radio waves that returns from the tag into digital data, which can be passed on to an information processing system in management applications [26]. In its most simple form, RIFD system consists of tags (transponder) with an antenna, a reader (interrogator) with an antenna which can be connected to the host terminal [27]. Figure 2 shows these components.

A RFID tag is an electronic label and can be identified as a portable memory device on a chip, which is encapsulated in a protective shell and can be attached to any object. RFID tags come in a wide variety of physical forms, shapes, sizes, and protective housings. The



Figure 1: A typical RFID system. 


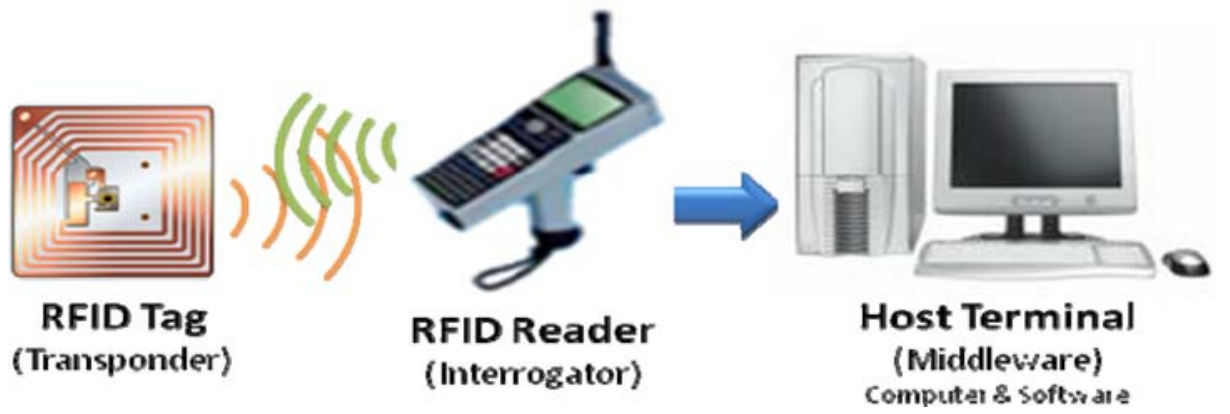

Figure 2: RFID system components.

encapsulation can come in a variety of sizes and forms, which protects the antenna and chip from environmental conditions or reagents. RFID tags can be distinguished into two broad groups depending on their power supply: those which have in-built battery (active tags) and those without (passive tags). Active tags are powered using their built-in battery, while passive tags are powered solely by the electromagnetic field generated by the RFID reader. Active tags are normally read and write devices, while passive tags are usually read only. Passive tags have an unlimited lifetime and are smaller, lighter, and cheaper. They have limited data storage capability, a shorter read range and they require a higher power from the reader. Active tags have internal battery source and therefore have shorter lifetime of approximately three to ten years [28]. They can read, write, and store significant amount of information and can be attached to sensors to store and communicate data to and from these devices. Some tags have an light-emitting diode (LED) that notifies the user with a blinking light when a tag and a reading device are communicating.

With active tags, the RFID tag is combined with sensor, enabling the active tag to sense the environment. This sensing capacity can be for environmental monitoring. Sensors could be geared to a wide variety of conditions, including: altitude, chemical and electrical properties, flow, imaging, level, motion, positioning, pressure, proximity, shock and vibration, speed, and temperature [29].

Reading and writing ranges depend on the operation frequency (low, high, ultra high, and microwave). Low frequency systems generally operate at 125-134 KHz. High frequency systems operates at $13.56 \mathrm{MHz}$, ultra high frequency (UHF) use a band anywhere from 433 to $956 \mathrm{MHz}$, and microwave operates at 2.45-5.8 GHz [27]. Tags operating at UHF typically have longer reading ranges than tags operating at other frequencies. Similarly, active tags have typically longer reading ranges than passive tags.

The significant advantage of all types of RFID systems is the noncontact, non-line-of-sight nature of the technology for reading and writing. In addition, a large number of RFID tags can be read almost instantaneously through other materials and they can be read through plastic, cardboard, and wood. The RFID tags can store data and can also be read in challenging circumstances at remarkable speeds, in most cases responding in less than $100 \mathrm{~ms}$. In interactive applications, such as work-in-process or maintenance tracking, the read and write capability of an active RFID system is also a significant advantage. RFID tags are reusable and less susceptible to damage and can be read through a variety of substances, such as ice, snow, paint, fog, crusted grime, and other visually and environmentally challenging conditions, where other technologies would be useless. 
This innovative technology has already been extensively applied in various industries, such as manufacturing; food; defense; pharmaceutical; transport; tracking library books; retail; and healthcare [30]. RFID technology is being successfully used for applications in the construction industry, such as asset management, theft deterrence, access control, and materials management.

\subsection{Ultrasonic sensors}

Ultrasonic sensors are widely used in industrial applications to measure object distance recently. The operating principle is based on the measurement of the Time of Flight (ToF), which is the time required for an ultrasonic wave to travel from a transmitter to a receiver. In ToF technique, object distance (D) from the receiver is evaluated by $\mathrm{D}=\mathrm{V} \times \mathrm{ToF}$, where $\mathrm{V}$ is the sound velocity [31].

\subsection{General Packet Radio System}

General Packet Radio Systems (GPRS) is a non-voice value added service that allows data to be sent and received across a mobile telephone network that was designed to run on GSM, a worldwide standard for cellular communications. GPRS is a packet switched 'always on' technology supporting internet protocols (IP) with a theoretical maximum speed of up to $114 \mathrm{kbps}$. GPRS is a wireless data transmission technology, which is related to Multimedia Messaging Service (MMS) and Internet Communications Service (ICS). In other words, GPRS can send any sort of messages that includes text, pictures, and sound and there is no limit to the amount of data that can be sent. In GPRS, when information is sent from one, it travels directly to the other almost immediately. Because GPRS uses the same protocols as the internet, the networks can be seen as subsets of the internet, with the GPRS devices as hosts, potentially with their own IP addresses [32].

\section{RFID APPLICATIONS IN DIFFERENT INDUSTRIES}

There are various applications of RFID technology in different industries. Some of the sectors where RFID technology has already been applied are manufacturing food, defense, pharmaceutical, transport, retail, and healthcare. [33].

In the construction industry, RFID technology has been applied in some efforts to improve tracking, delivery, receipt, and location of materials and components, such as fabricated pipes, structural steel members, engineered-to-order components, and interior decorating materials in lay down yards and under shipping [34]. The findings of a number of researches demonstrated that locating buried assets by applying RFID technology has a great potential for facilitating the accurate 3D data of underground infrastructure [35]. In addition, RFID technology has been used to develop a traceability system between paving operation and the asphalt mixing plant [36], reliable security and safety system for the construction site [37], and has been implemented to improve the management of health and safety in construction [38-40]. Furthermore, RFID technology has been utilized in simulation-based framework for modeling information flow processes in highway project [41], ubiquitous system for context-specific information delivery [42], mobilized information frame in production management system [43], and last but not the least, lifecycle management of facilities and building components [44,45].

\section{ARCHITECTURE OF THE PROPOSED SYSTEM}

The RFID-based pervasive system developed in this research is divided into two major parts, first the field or on-site monitoring system and second the office data processing system. 


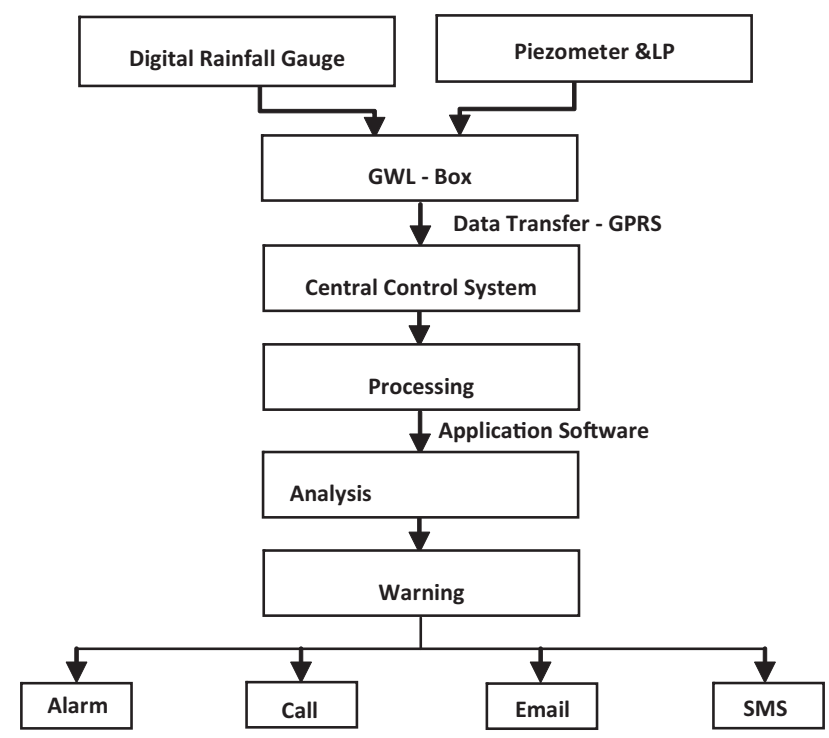

Figure 3: The system implementation flow diagram.

The on-site system mainly consists of three types of hardware components, namely, (i) Groundwater Level Box (GWL-box) consisting of the transmitter/receiver, GSM module; (ii) digital rainfall gauge; (iii) Leveling Package (LP) which consists of an active RFID tag coupled with ultrasonic sensor, this also equipped with a temperature sensor. GSM communication technology is the second part of the mobile pervasive system where the information is retrieved from transmitter/receiver device and is transferred to the server using GPRS. Finally, the Data Processing System consists of two servers, the application server (e.g. GIS system) and the database server with warning system. The architecture of the system and the schematic model of collection, transmission and management of data are shown in Fig. 3.

\section{IMPLEMENTATION}

To meet the requirements of real-time monitoring of the changes in pore-water pressure in a given area, an intelligent network system gathers the required information continuously. The monitoring system, which combines sensor technologies with traditional method of groundwater level monitoring, piezometers, consists of the following subsystems:

\subsection{System installation and setup}

First of all, piezometers are located based on the geological and topographical maps of the area, using expert judgment. The numbers and location of piezometers can also be optimized using a neural network algorithm, if necessary. For leveling up the water inside the piezometers, they have been left to stabilize. The main part of the proposed system is placed in the piezometer. The main function of this part is measuring the water level. This part of the system which is named LP consists of an active RFID tag coupled with an ultrasonic sensor equipped with a temperature sensor.

This subsystem floats on the existing water in the piezometer using a small balloon. It has the capability to receive RF waves and sends RF-ultrasound waves to and from the transmitter 
and receiver. Figure 4 illustrates a schematic scheme of the automated groundwater level monitoring system.

The heart of the system is the GWL-box. This includes a transmitter/receiver and GSM module. The GWL-box sends the collected data continuously, however, to detect the box from landsliding; it is highly recommended to install the box on a concrete platform and in the more stable zone of the area. The transmitter/receiver can collect the data regarding the water level from the piezometer and also get rainfall data from the recorder by wire.

As illustrated in Fig. 5, the transmitter and receiver can be packed and secured as the cap of the piezometer. The main performance of this part of the system is sending RF waves toward the active RFID-Sensors (LP) and receiving RF and ultrasound waves from the LP as well as transfer of the collected data to GWL-box.

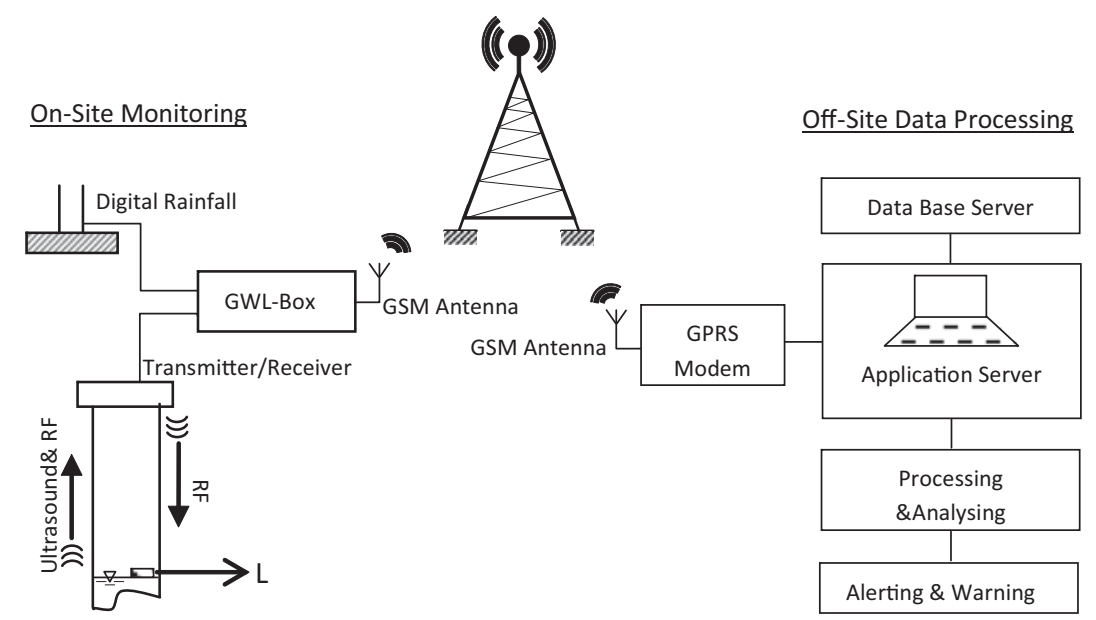

Figure 4: Schematic scheme of the automated groundwater monitoring system.

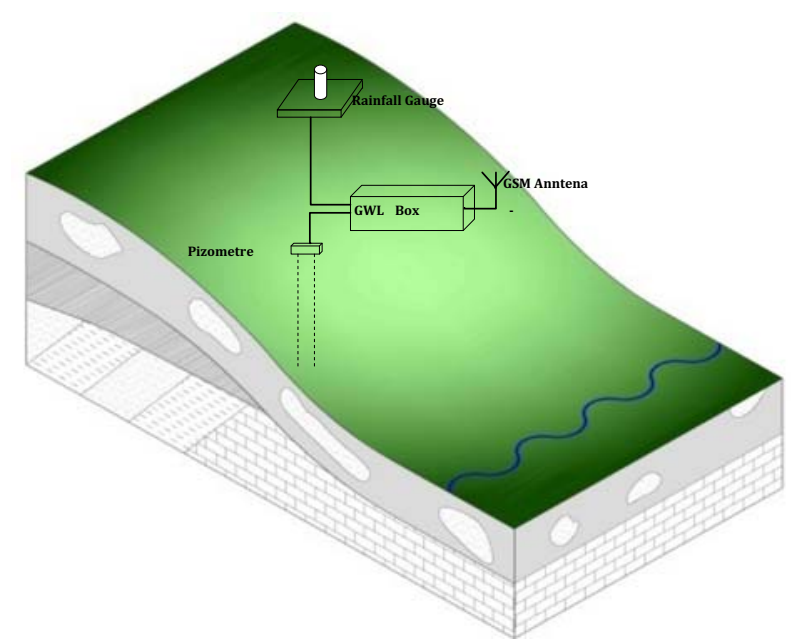

Figure 5: Schematic model of system installation. 
The last on-site subsystem which is installed and connected directly to GWL-box is a digital rainfall recorder. This peripheral device has the capability of data retrieval by data shuttling directly to GWL-box and is equipped with a solar power supply.

This linkage between the two subsystems, LP and digital rainfall gauge, provides the advantage of continuous data collection even in adverse climatic conditions, so that sophisticated data collection is possible for slope instability prediction in the figure 5 .

\subsection{Triggering and depth calculation}

As it was mentioned, the LP floats on the water inside the piezometer measuring its water level. On the measurements of ToF for RF to estimate the distance of tag from the receiver, the delay is attributed to the speed of RF (very fast travelling) signals in the space. To find a solution for this issue and to have a more accurate measurement for distance, an ultrasound signal is used to measure the distance of sensor from the receiver. Therefore, an estimation of distance starts with a query from transmitter and at the same time a timer starts and the tag responds to the ultrasound signal within a short time after a querying of the receiver. Thus, the signal travels with the speed of light in the forward direction and with the speed of ultrasound in the backward direction where the speed of ultrasound signals is about $340 \mathrm{~m} / \mathrm{s}$ which is significantly slower than the speed of light (one million times slower than the speed of light). Therefore, small delays identified by scheduling the sensor do not cause an error in estimation of distance and we can ignore the component of the delay recognized by the small processing or scheduling delay at the sensor, or the propagation delay of RF signal in the forward direction. The ultrasound signal does not carry in digital information; thus, RFID active tag has been selected for transferring data, such as temperature, which is connected to the tag.

The intensity of the ultrasonic wave generated by the transmitter and the sensitivity of the receiver depends on the temperature of the environment which leads to a strong temperature dependence of the reflected intensity. The propagation time also depends on the temperature of the propagation environment (i.e. air).

The speed of sound in air actually depends on the temperature of the air. As a standard, it is accepted that the speed of sound is $340 \mathrm{~m} / \mathrm{s}$ at $15^{\circ} \mathrm{C}$. To calculate the speed of sound at a different temperature, the following formula is used:

$$
1 \mathrm{v}=331.5 \mathrm{~m} / \mathrm{s}+0.6 T
$$

where ' $\mathrm{v}$ ' is the velocity of sound $(\mathrm{m} / \mathrm{s})$ and $T$ is the temperature $\left({ }^{\circ} \mathrm{C}\right)$.

For example, the properties of sound in air with temperature $T=20^{\circ} \mathrm{C}$ are: Frequency $=$ $500 \mathrm{~Hz}$, Velocity $\mathrm{V}=343.7 \mathrm{~m} / \mathrm{s}$, and Wavelength $=0.6874 \mathrm{~m}$. Therefore, distance of tag (groundwater level) is expressed by:

$$
\mathrm{D}=\mathrm{V} \times t
$$

where ' $t$ ' is the propagation time.

To calibrate dependencies on temperature mentioned above, a RFID tag connected to a temperature sensor has been selected to monitor temperature of the environment. The system is based on the definite interval time to capture and transfer the data remotely. The system can be programmed and interval time can be changed according to the seasonal demands. 


\subsection{Data collection and transmission}

At the allocated interval time, the upper part of the piezometer triggers which sends RF waves to get radio frequency and ultrasound from LP. This data contains the proper information which is necessary to calculate water level according to the temperature. The GWL-box (Fig. 6) collects the information from transmitter. Then it first stores the collected data and transfers them to the main server using GPRS technology.

\subsection{Data processing and warning}

The prime location of devices, GWL-box, LP rainfall gauge, is identified with a unique ID. The GWL-box sends the collected data via GSM. When the data has been transferred to the main central computer, it can be recognized from the device data it was sent from. Special software has been written to calculate and correlate water levels and illustrate the water table and pore water pressures on real-time bases, graphically. The processed data is used for slope stability analysis and a factor of safety is calculated. Thereafter, it is possible to predict what will happen in the next few hours and further potential dangers can be recognized in the preanalyses of the slopes. While the factor of safety approaches one, a warning procedure is released. At this stage, the results can be shown on a GIS map to recognize the slope failure location and the areas at risk. Then by means of the internet and GSM technology, results are distributed, first to authorized people who are responsible for the area as well as the alert signals which are set up in the endangered area. The warning system has the ability to send

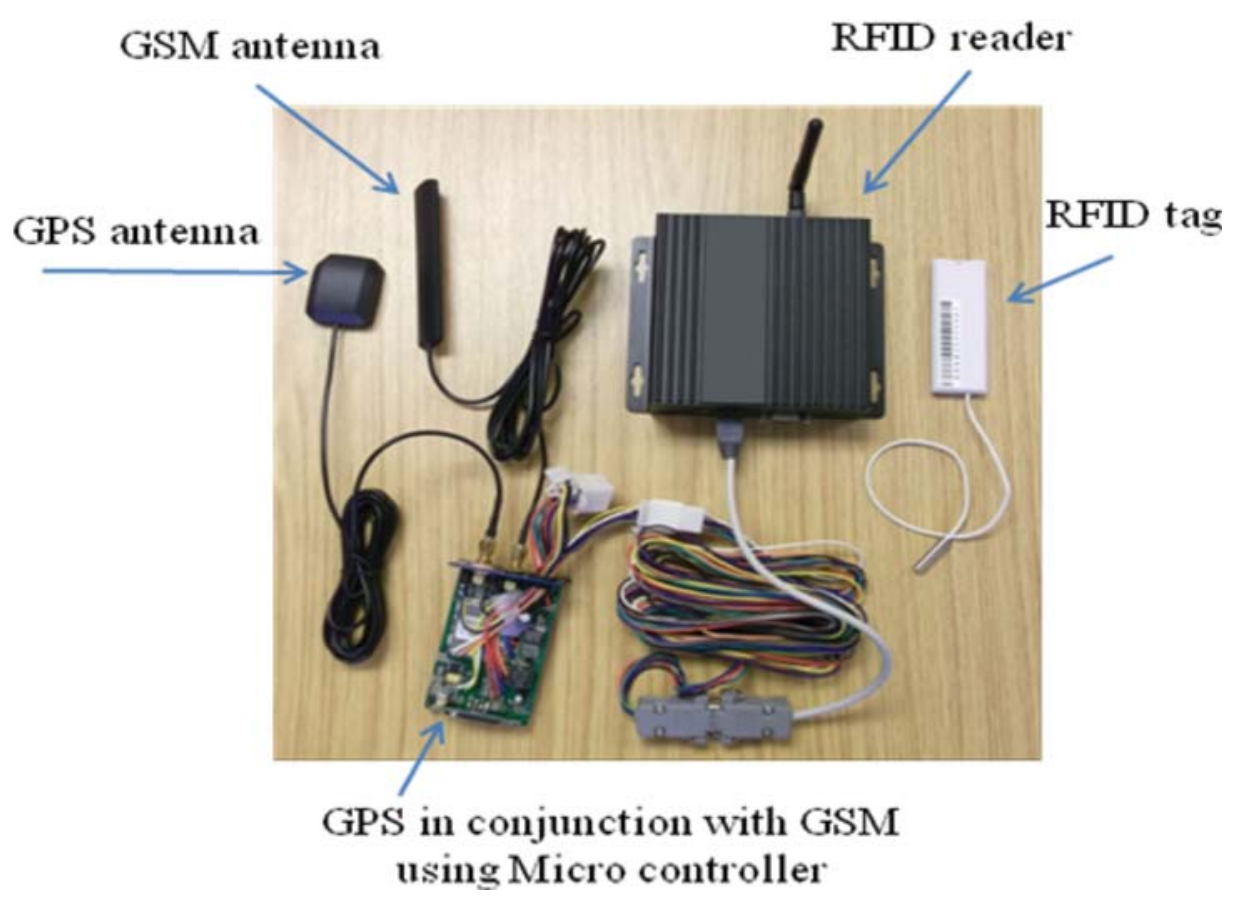

Figure 6: The GWL-box. 
text messages to provided mobile telephone numbers, and send email to local authorities to trigger the installed alarms.

\section{CONCLUSIONS}

The applications of RFID-based integrated system is used in this research to automate the task of landslides monitoring and early warning by means of acquire groundwater table and pore-water pressure on a real-time bases. This research is conducted to identify opportunities for applying advanced tracking and data storage technologies in landslides monitoring and early warnings and to develop a model that explores how these technologies can be used in landslide monitoring. Combination of RFID technology with GPRS and sensor technologies provide low-cost, low energy consumption and timely active groundwater information on the slope areas with greater accuracy. In addition, when the system is combined with rainfall gauges, it has the capability of providing reliable data for understanding the mechanisms and processes in which shallow and rainfall-triggered landslides occurred, and subsequently the real relationships between rainfall infiltration and groundwater table can be obtained. Such intelligent systems permit real-time control, enabling actions to be taken which will save valuable time.

\section{REFERENCES}

[1] Petley, D., Mantovani, F., Bulmer, M. \& Zannoni, A., The use of surface monitoring data for the interpretation of landslide movement patterns. Geomorphology, 66, pp. 133-147, 2005. doi: http://dx.doi.org/10.1016/j.geomorph.2004.09.011

[2] Ayalew, L., Yamagishi, H., Marui, H. \& Kanno, T., Landslides in Sado Island of Japan: Part I. Case studies, monitoring techniques and environmental considerations. Engineering Geology, 81, pp. 419-431, 2005. doi: http://dx.doi.org/10.1016/j.enggeo.2005.08.005

[3] Xiao-gen, L., An-ming, W. \& Zong-min, W., Stability analysis and monitoring study of JIJIA river landslide based on WebGIS. Journal of Coal Science \& Engineering, 16, pp. 41-46, 2010. doi: http://dx.doi.org/10.1007/s12404-010-0108-7

[4] Cigna, F., Del Ventisette, C., Liguori V. \& Casagli, N. Advanced radar-interpretation of InSAR time series for mapping and characterization of geological processes. Natural Hazards and Earth System Sciences, 3, pp. 865-881, 2011. doi: http://dx.doi. org/10.5194/nhess-11-865-2011

[5] Gigli, G., Fanti, R., Canuti, P. \& Casagli, N. Integration of advanced numerical modeling and monitoring techniques for the comprehensive analysis of risk scenario rockslides: the case of Mt goods (Florence, Italy). Engineering Geology, 18(3), pp. 48-59, 2011. doi: http://dx.doi.org/10.1016/j.enggeo.2011.03.017

[6] Peyret, M., Djamour, Y., Rizza, M., Ritz, J., Hurtrez, J., Goudarzi, M., Nankali, H., Chery, J., Ledortz, K. \& Uri, F., Monitoring of the large slow kahrod landslide in alborz mountain range (Iran) by GPS and SAR interferometry, Eng.Geol., 100(3-4), pp. 131-141, 2008. doi: http://dx.doi.org/10.1016/j.enggeo.2008.02.013

[7] Borgogno Mondino, E., Giardino, M. \& Perotti, L., A neural network method for analysis of hyperspectral imagery with application to the cassas landslide (Susa Valley, NW-Italy), Geomorphology, 110(1-2), pp. 20-27, 2009._doi: http://dx.doi. org/10.1016/j.geomorph.2008.12.023

[8] Baldo, M., Bicocchi, C., Chiocchini, U., Giordan, D. \& Lollino, G., LIDAR monitoring of mass wasting processes: the radicofani landslide, province of Siena, central 
Italy. Geomorphology, 105(3-4), pp. 193-201, 2009. doi: http://dx.doi.org/10.1016/j. geomorph.2008.09.015

[9] Kumar, S. \& Ramesh, M.V., Lightweight management framework (LMF) for a heterogeneous wireless network for landslide detection, Proc. of the Int. Multi-Conf. On NeCoM 2010, WiMoN 2010, WeST 2010, eds. N. Meghanathan, S. Boumerdassi, N. Chaki \& D. Nagamalai, Springer, pp. 457-471, 2010.

[10] Hosseyni, S., Bromhead, E.N., Majrouhi Sardroud, J., Limbachiya, M. \& Riazi, M., Integrated RFID and sensor technologies for effective landslide monitoring and early warning, Modern Methods and Advance in Structural Engineering and Construction, eds. S. Cheung, S. Yazdani, N. Ghafoori \& A. Singh, Research Publishing: Singapore, 2011.

[11] Okimura1, T., Torii, N., Osaki, Y., Nanbu, M. \& Haraguchi, K., Improvement of prediction accuracy of system of real-time type hazard map of slope failure disasters caused by heavy rainfalls, Geotechnical Engineering Journal of the SEAGS \& AGSSEA, 41(2) 2010.

[12] Bonomi, T. \& Cavallin, A., Three-dimensional hydrogeological modelling application to the Alvera mudslide (Cortina d'Ampezzo, Italy). Geomorphology, 30, pp. 189-199, 1999. doi: http://dx.doi.org/10.1016/S0169-555X(99)00054-9

[13] Blumberg, D., Freilikher, V., Lyalko, I., Vulfson, L., Kotlyar, A., Shevchenko, V. \& Ryabokonenko, A., Soil moisture (water-content) assessment by an airborne scatterometer: the chernobyl disaster area and the negev desert. Remote Sensing of Environment, 71, pp. 309-319, 2000. doi: http://dx.doi.org/10.1016/S0034-4257(99)00087-5

[14] Sato, M. \& Lu, Q., Ground water migration monitoring by GPR, Proc. of the IEEE Int. Conf. On Geoscience and Remote Sensing, pp. 345-347, 2002.

[15] Basile, A., Mele, G. \& Terribile, F., Soil hydraulic behaviour of a selected benchmark soil involved in the landslide of Sarno 1998. Geoderma, 117(3-4), pp. 331-346, 2003. doi: http://dx.doi.org/10.1016/S0016-7061(03)00132-0

[16] Jiao, J., Wang, X. \& Nandy, S., Confined groundwater zone and slope instability in weathered igneous rocks in Hong Kong. Engineering Geology, 80, pp. 71-92, 2005. doi: http://dx.doi.org/10.1016/j.enggeo.2005.04.002

[17] Friedel, S., Thielen, A. \& Springman, S., Investigation of a slope endangered by rainfall-induced landslides using 3D resistivity tomography and geotechnical testing. Journal of Applied Geophysics, 60, pp. 100-114, 2006. doi: http://dx.doi.org/10.1016/j. jappgeo.2006.01.001

[18] Pan, S., Wang, Z., Su, Q., Sun, T. \& Zhang, Y., Groundwater level monitoring model using multi-temporal image in Arid region of northwest China, The International Archives of the Photogrammetry, Remote Sensing and Spatial Information Sciences, XXXVII, pp. 745-750, 2008.

[19] Stangl, R., Buchan, G. \& Loiskand, W., Field use and calibration of a TDR-based probe for monitoring water content in a high-clay landslide soil in Austria, Geoderma, 150, pp. 23-31, 2009. doi: http://dx.doi.org/10.1016/j.geoderma.2009.01.002

[20] Tu, X., Kwong, A., Dai, F., Tham, L. \& Min, H., Field monitoring of rainfall infiltration in a loess slope and analysis of failure mechanism of rainfall-induced landslides. Engineering Geology, 105, pp. 134-150, 2009. doi: http://dx.doi.org/10.1016/j. enggeo.2008.11.011

[21] Quinn, N., Ortega, R., Rahilly, P. \& Royer, C., Use of environmental sensors and sensor networks to develop water and salinity budgets for seasonal wetland real-time water 
quality management. Environmental Modelling \& Software, 25, pp. 1045-1058, 2010. doi: http://dx.doi.org/10.1016/j.envsoft.2009.10.011

[22] Hosseyni, S., Bromhead, E.N., Majrouhi Sardroud, J., Limbachiya, M.C. \& Riazi, M., Real-time landslides monitoring and warning using RFID technology for measuring ground water level, Proc. of the $2^{\text {nd }}$ Int. Conf. On Disaster Management and Human Health: Reducing Risk, Improving Outcomes, eds. C. A. Brebbia \& A. J. Kassab, WIT Press: UK, 2011.

[23] Majrouhi Sardroud, J. \& Limbachiya, M.C., Effective information delivery at construction phase with integrated application of RFID, GPS and GSM technology. Lecture Notes in Engineering and Computer Science, 2183(1), pp. 425-431, 2010.

[24] Domdouzis, K., Kumar, B. \& Anumba, C., Radio frequency identification (RFID) applications: a brief introduction. Adv. Eng. Inform., 21(4), pp. 350-355, 2007.

[25] Majrouhi Sardroud, J. \& Limbachiya, M.C., Towards linking islands of information within construction projects utilizing RF technologies (Chapter 17). Electrical Engineering and Applied Computing, eds. L. Gelman, \& S. I. Ao, London: Springer, pp. 197-207,2011.

[26] Shepard, S., RFID: Radio Frequency Identification, McGraw-Hill: NY, 2005.

[27] Finkenzeller, K., RFID Handbook: Fundamentals and Applications in Contactless Smart Cards and Identification, John Wiley \& Sons, Ltd.: Wiltshire, UK, 2010.

[28] Jaselskis, E.J., \& El-Misalami, T., Implementing radio frequency identification in the construction process. J. Constr. Eng. Manage. -ASCE, 129(6), pp. 680-688, 2003. doi: http://dx.doi.org/10.1061/(ASCE)0733-9364(2003)129:6(680)

[29] Malone, R., Sensing the future. Inbound Logistics, 24(12), pp. 18-19, 2004.

[30] Majrouhi Sardroud, J., Limbachiya, M.C. \& Saremi, A.A., An overview of RFID applications in construction industry. Proc. of The $3^{\text {rd }}$ Int. RFID Conference, Tehran, IRAN, 2009.

[31] Majrouhi Sardroud, J. \& Limbachiya, M.C., Utilization of advanced data storage technology to conduct construction industry on clear environment, Journal of World Academy of Science. Engineering and Technology, 66, pp. 808-813, 2010.

[32] Ward, M., Thorpe, T., Price, A. \& Wren, C., Implementation and control of wireless data collection on construction sites. Electronic Journal of Information Technology in Construction, 9, pp. 297-311, 2004. (doi: http://www.itcon.org/cgi-bin/works/ Show?2004 21).

[33] Ngai, E.W.T., Moon, K.K.L., Riggins, F.J. \& Yi, C.Y., RFID research: An academic literature review (1995-2005) and future research directions. International Journal of Production Economics, 112(2), pp. 510-520, 2008. doi: http://dx.doi.org/10.1016/j. ijpe.2007.05.004

[34] Majrouhi Sardroud, J., Influence of RFID technology on automated management of construction materials and components, Scientia Iranica, Transactions A: Civil Engineering, 19(3), pp. 381-392, 2012. doi: http://dx.doi.org/10.1016/j.scient.2012.02.023

[35] Dziadak, K., Kumar, B. \& Sommerville, J., Model for the 3D location of buried assets based on RFID technology. Journal of Computing in Civil Engineering, 23(3), pp. 148-159, 2009. doi: http://dx.doi.org/10.1061/(ASCE)0887-3801(2009)23:3(148)

[36] Peyret, F. \& Tasky, R., A traceability system between plant and work site for asphalt pavements. Computer-Aided Civil and Infrastructure Engineering, 19(1), pp. 54-63, 2004. doi: http://dx.doi.org/10.1111/j.1467-8667.2004.00337.x 
[37] Abderrahim, M., Garcia, E. Diez, R. \& Balaguer, C., A mechatronics security system for the construction site. Automation in Construction, 14(4), pp. 460-466, 2005. doi: http://dx.doi.org/10.1016/j.autcon.2004.09.007

[38] Riaz, Z., Edwards, D.J. \& Thorpe, A., SightSafety: a hybrid information and communication technology system for reducing vehicle/pedestrian collisions. Automation in Construction, 15(6), pp. 719-728, 2006. doi: http://dx.doi.org/10.1016/j. autcon.2005.09.004

[39] Chae, S. \& Yoshida, T., Application of RFID technology to prevention of collision accident with heavy equipment. Automation in Construction, 19(3), pp. 368-374, 2010. doi: http://dx.doi.org/10.1016/j.autcon.2009.12.008

[40] Wu, W., Yang, H., Chew, D.A.S., Yang, S.H., Gibb, A.G.F. \& Li, Q., Towards an autonomous real-time tracking system of near-miss accidents on construction sites. $\mathrm{Au}$ tomation in Construction, 19(2), pp. 134-141, 2010. doi: http://dx.doi.org/10.1016/j. autcon.2009.11.017

[41] Akinci, B., Kiziltas, S., Ergen, E., Karaesmen, I.Z. \& Keceli, F., Modeling and analyzing the impact of technology on data capture and transfer processes at construction sites: a case study. Journal of Construction Engineering and Management, 132(11), pp. 11481157, 2006. doi: http://dx.doi.org/10.1061/(ASCE)0733-9364(2006)132:11(1148)

[42] Behzadan, A.H., Aziz, Z., Anumba, C.J. \& Kamat, V.R., Ubiquitous location tracking for context-specific information delivery on construction sites. Automation in Construction, 17(6), pp. 737-748, 2008. doi: http://dx.doi.org/10.1016/j.autcon.2008.02.002

[43] Yin, S.Y.L., Tserng, H.P., Wang, J.C. \& Tsai, S.C., Developing a precast production management system using RFID technology. Automation in Construction, 18(5), pp. 677-691, 2009. doi: http://dx.doi.org/10.1016/j.autcon.2009.02.004

[44] Cheng, M.Y., Tsai, H.C., Lien, L.C. \& Kuo, C.H., GIS-based restoration system for historic timber buildings using RFID technology. Journal of Civil Engineering and Management, 14(4), pp. 227-234, 2008. doi: http://dx.doi.org/10.3846/ $\underline{1392-3730.2008 .14 .21}$

[45] Motamedi, A. \& Hammad, A., Lifecycle management of facilities components using radio frequency identification and building information model. Electronic Journal of Information Technology in Construction, 14, pp. 238-262, 2009. 